\title{
High plasma leptin levels confer increased risk of atherosclerosis in women with systemic lupus erythematosus, and are associated with inflammatory oxidised lipids
}

\author{
Maureen McMahon, ${ }^{1}$ Brian J Skaggs, ${ }^{1}$ Lori Sahakian, ${ }^{1}$ Jennifer Grossman, ${ }^{1}$ \\ John FitzGerald, ${ }^{1}$ Nagesh Ragavendra, ${ }^{2}$ Christina Charles-Schoeman, ${ }^{1}$ \\ Marissa Chernishof, ${ }^{1}$ Alan Gorn, ${ }^{1}$ Joseph L Witztum, ${ }^{3}$ Weng Kee Wong, ${ }^{5}$ \\ Michael Weisman, ${ }^{1,4}$ Daniel J Wallace, ${ }^{4}$ Antonio La Cava, ${ }^{1}$ Bevra H Hahn' ${ }^{1}$
}

\begin{abstract}
Additional data
(supplementary tables and figures) are published online only. To view these files please visit the journal online at (http://ard.bmj.com)

${ }^{1}$ Division/Department of Rheumatology, UCLA David Geffen School of Medicine, Los Angeles, California, USA ${ }^{2}$ Division/Department of Radiology, UCLA David Geffen School of Medicine, Los Angeles, California, USA ${ }^{3}$ Division of Endocrinology and Metabolism, University of California San Diego, La Jolla,

California, USA

${ }^{4}$ Division of Rheumatology, Cedars Sinai Medical Center, Los Angeles, California, USA ${ }^{5}$ Department of Biostatistics, UCLA David Geffen School of Medicine, Los Angeles, California, USA
\end{abstract}

\section{Correspondence to} Dr Maureen McMahon, Division/Department of Rheumatology, UCLA Medical Center, 32-59 Rehab Center, 1000 Veteran Avenue, Los Angeles, CA 90095, USA; mmcmahon@mednet.ucla.edu

Accepted 31 March 2011 Published Online First 13 June 2011

\begin{abstract}
Background Patients with systemic lupus erythematosus (SLE) are at increased risk of atherosclerosis, even after accounting for traditional risk factors. High levels of leptin and low levels of adiponectin are associated with both atherosclerosis and immunomodulatory functions in the general population.

Objective To examine the association between these adipokines and subclinical atherosclerosis in SLE, and also with other known inflammatory biomarkers of atherosclerosis.
\end{abstract}

Methods Carotid ultrasonography was performed in 250 women with SLE and 122 controls. Plasma leptin and adiponectin levels were measured. Lipoprotein a (Lp(a)), oxidised phospholipids on apoB100 (OxPL/apoB100), paraoxonase, apoA-1 and inflammatory high-density lipoprotein (HDL) function were also assessed.

Results Leptin levels were significantly higher in patients with SLE than in controls $(23.7 \pm 28.0$ vs $13.3 \pm 12.9 \mathrm{ng} / \mathrm{ml}, \mathrm{p}<0.001)$. Leptin was also higher in the 43 patients with SLE with plaque than without plaque $(36.4 \pm 32.3$ vs $20.9 \pm 26.4 \mathrm{ng} / \mathrm{ml}, \mathrm{p}=0.002)$. After multivariate analysis, the only significant factors associated with plaque in SLE were leptin levels in the highest quartile ( $\geq 29.5 \mathrm{ng} / \mathrm{ml})(\mathrm{OR}=2.8, \mathrm{p}=0.03)$, proinflammatory HDL (piHDL) $(O R=12.8, p<0.001)$, age $(\mathrm{OR}=1.1, \mathrm{p}<0.001)$, tobacco use $(\mathrm{OR}=7.7, \mathrm{p}=0.03)$ and hypertension $(\mathrm{OR}=3.0, \mathrm{p}=0.01)$. Adiponectin levels were not significantly associated with plaque in our cohort. A significant correlation between leptin and piHDL function ( $p<0.001)$, Lp(a) $(p=0.01)$ and OxPL/apoB100 $(p=0.02)$ was also present.

Conclusions High leptin levels greatly increase the risk of subclinical atherosclerosis in SLE, and are also associated with an increase in inflammatory biomarkers of atherosclerosis such as piHDL, Lp(a) and OxPL/ apoB100. High leptin levels may help to identify patients with SLE at risk of atherosclerosis.

Young women with systemic lupus erythematosus (SLE) have up to a 50 times higher risk of cardiovascular events than age-matched controls, ${ }^{1}$ even after consideration of traditional Framingham risk factors. ${ }^{1-3}$ It has increasingly become evident that inflammation and immune mechanisms play an important role in the pathogenesis of atherosclerosis in SLE, and that new methods are needed to predict which patients with SLE are at risk of cardiovascular morbidity.

The adipokine leptin functions as a hypothalamic modulator of food intake, body weight and fat stores. ${ }^{4}$ High circulating leptin levels are seen in overweight individuals, ${ }^{56}$ suggesting that obese patients develop leptin resistance similar to insulin resistance in type II diabetes. ${ }^{7}$ Hyperleptinaemia in the general population is also associated with atherosclerosis, hypertension and metabolic syndrome. $^{5} 8$ Conversely, adiponectin is the most abundant human plasma adipocytokine, and levels are reduced in type II diabetes and cardiovascular disease (CVD). ${ }^{9}$ In addition to the established role of adipokines in energy homoeostasis, leptin and adiponectin also have immunomodulatory roles. ${ }^{10}$ The dual roles of adipokines in the regulation of metabolism and the immune system have led some investigators to postulate that adipokines may provide a link between immune responses and atherosclerosis. ${ }^{10}$

Several previous small cohort studies have shown elevated leptin and adiponectin levels in adult $^{5} 11 \quad 12$ and paediatric ${ }^{13}$ patients with SLE. This study was designed to determine if leptin and adiponectin levels predict subclinical atherosclerosis in SLE. Furthermore, we sought to examine whether adipokine levels are associated with other inflammatory biomarkers of atherosclerosis in SLE such as proinflammatory high-density lipoprotein (piHDL), oxidised phospholipid (OxPL)/apoB100 ratio and lipoprotein a ( $\mathrm{Lp}(\mathrm{a}))$.

\section{METHODS}

\section{Study population}

Two hundred and fifty patients with SLE and 122 controls from our longitudinal Biomarkers of Atherosclerosis in SLE Cohort Study were included, based on the availability of baseline plasma samples. No significant demographic or clinical differences existed between subjects included here in comparison with the larger cohort. Study protocol details have been reported elsewhere. ${ }^{14}$ In brief, participants were recruited prospectively from the rheumatology practices of the University of California Los Angeles (UCLA) and Cedars Sinai Medical Center in Los Angeles between February 2004 and February 2008. Eligible participants were 
women aged $\geq 18$ years. Patients with SLE fulfilled at least four of the 1997 revised American College of Rheumatology (ACR) classification criteria for SLE. ${ }^{15}$ The controls were women, healthy by self-report, with no clinical manifestations of SLE on Connective Tissue Screening Questionnaire. ${ }^{16}$ Because statins $^{17}$ and renal failure ${ }^{18}$ are known to alter HDL inflammatory function (one of the target biomarkers of the study), subjects were excluded if they had taken statins within the previous 3 months, or if they had renal failure (defined as creatinine $>2.0 \mathrm{mg} / \mathrm{dl}$ ). Demographic data are shown in table 1 . The study was approved by the institutional review boards at UCLA and Cedars-Sinai Medical Center; all participants gave written informed consent.

\section{Sample collection}

All eligible consenting subjects provided a blood sample, underwent a carotid ultrasound and completed a set of questionnaires. Plasma lipids and levels of high-sensitivity C-reactive protein were measured in the UCLA clinical laboratory by standard methods. On the day of plasma sampling, SLE disease activity was assessed using Safety of Estrogens in Lupus ErythematosusNational Assessment/SLE Disease Activity Index. ${ }^{19}$ Organ damage was determined using the Systemic Lupus International Collaborating Clinics/ACR Damage Index (SDI). ${ }^{20}$ Height and weight were measured, and body mass index (BMI) was calculated. Information about cardiac risk factors and current drugs were obtained from self-administered health history questionnaires and confirmed by a study doctor using chart review.

\section{Carotid ultrasound}

B (brightness)-mode grey scale, colour and spectral Doppler techniques were used to investigate the carotid arteries according to a standardised protocol. ${ }^{14}$ The same radiologist (NR) interpreted all studies in a blinded fashion, and the same ultrasound unit (Iu22; Philips Medical Systems, Bothell, Washington, USA) was used for scanning all participants.

The following anatomical sites were examined for the presence of atherosclerotic plaque, defined as the presence of focal protrusion into the arterial lumen with a thickness exceeding that of the surrounding wall by at least $50 \%$ : the bilateral common carotid, internal carotid, external carotid and vertebral arteries, and the carotid bulbs. The number, location and sonographic appearance of the plaques were recorded. Intima-media thickness (IMT) of the far wall of the distal common carotid artery was measured (1) $1 \mathrm{~cm}$ proximal to the flow divider, (2) at end diastole and (3) using automated OLAB software (Philips Medical Systems). IMT was never measured at the level of a plaque and is presented as the average of three values of the left and right segments.

\section{Measurement of inflammatory lipids and adipokines}

Plasma leptin (BioVendor, Candler, North Carolina, USA), adiponectin (R\&D Systems, Minneapolis, Minnesota, USA) and apoA-1 levels (Mabtech, Cincinnati, Ohio, USA) were measured using ELISA. HDL function was measured as described. ${ }^{14}$ Values $\geq 1.0$ after the addition of test HDL-cholesterol indicated dysfunctional, piHDL; values $<1.0$ indicated normal, anti-inflammatory HDL. Plasma paraoxonase (PON1) activity was measured using paraoxon as a substrate as described. ${ }^{21} \mathrm{Lp}(\mathrm{a})$ was measured as described, ${ }^{22}$ and levels of OxPL/apoB100 were detected with the monoclonal antibody E $06^{22}$ in a subset of 179 patients with SLE (the first 179 subjects enrolled in the study). For each assay, the interassay and intra-assay variation was $<8 \%$.
Table 1 Demographic and clinical data of patients with systemic lupus erythematosus (SLE) and healthy controls*

\begin{tabular}{|c|c|c|c|}
\hline Characteristics & SLE $(n=250)$ & Control $(n=122)$ & p Value ${ }^{\dagger}$ \\
\hline Age (years, (mean \pm SD)) & $42.0 \pm 13.1$ & $41.4 \pm 13.5$ & NS \\
\hline $\begin{array}{l}\text { Total cholesterol }(\mathrm{mg} / \mathrm{dl}, \\
(\text { mean } \pm \text { SD)) }\end{array}$ & $185.1 \pm 43.2$ & $183.5 \pm 48.0$ & NS \\
\hline $\mathrm{HDL}(\mathrm{mg} / \mathrm{dl},($ mean $\pm \mathrm{SD}))$ & $56.3 \pm 16.8$ & $58.3 \pm 15.6$ & NS \\
\hline LDL (mg/dl, (mean \pm SD)) & $105.8 \pm 34.7$ & $104.8 \pm 43.8$ & NS \\
\hline $\begin{array}{l}\text { Triglycerides } \\
\text { (mg/dl, (mean } \pm S D))\end{array}$ & $112.9 \pm 70.5$ & $108.4 \pm 52.9$ & NS \\
\hline $\begin{array}{l}\text { High-sensitivity CRP } \\
\text { (mg/l, (mean } \pm \text { SD)) }\end{array}$ & $2.8 \pm 6.7$ & $2.0 \pm 3.2$ & NS \\
\hline $\begin{array}{l}\text { History of previous CVD } \\
(\%(\mathrm{n}))^{\ddagger}\end{array}$ & $8.4(21)$ & 0 & $<0.001$ \\
\hline Body mass index & $26.1 \pm 6.5$ & $24.2 \pm 5.1$ & 0.002 \\
\hline $\begin{array}{l}\text { Family history of CAD } \\
(\%(n))\end{array}$ & $24.8(62)$ & $18.0(22)$ & NS \\
\hline $\begin{array}{l}\text { History of hypertension } \\
(\%(n))^{\S}\end{array}$ & $30.8(77)$ & $16.4(20)$ & 0.003 \\
\hline History of diabetes $(\%(n))^{\pi}$ & $5.2(13)$ & $0.8(1)$ & 0.04 \\
\hline $\begin{array}{l}\text { History of smoking (current) } \\
(\%(n))^{* *}\end{array}$ & $7.6(19)$ & $12.3(15)$ & NS \\
\hline $\begin{array}{l}\text { Mean intima-media } \\
\text { thickness }\left(\mathrm{mm}^{2}\right. \\
(\mathrm{mean} \pm \mathrm{SD}))\end{array}$ & $0.55 \pm 0.14$ & $0.54 \pm 0.13$ & NS \\
\hline $\begin{array}{l}\text { Presence of carotid plaque } \\
\text { (yes, no) }(\%(n))\end{array}$ & $17.2(43)$ & $13.1(16)$ & NS \\
\hline \multicolumn{4}{|l|}{ Ethnicity $(\%(n))$} \\
\hline Caucasian & $49.2(123)$ & $59.8(73)$ & \\
\hline Asian or Pacific Islander & $13.2(33)$ & $21.3(26)$ & \\
\hline African American & $12.8(32)$ & $9.0(11)$ & \\
\hline Hispanic & $18.4(46)$ & $8.2(10)$ & \\
\hline Mixed or other & $6.4(16)$ & $1.6(2)$ & \\
\hline Leptin (ng/ml, (mean $\pm S D))$ & $23.7 \pm 28.0$ & $13.3 \pm 12.9$ & $<0.001$ \\
\hline $\begin{array}{l}\text { Adiponectin } \\
(\mu \mathrm{g} / \mathrm{ml},(\text { mean } \pm \mathrm{SD}))\end{array}$ & $15.3 \pm 8.4$ & $14.0 \pm 7.8$ & NS \\
\hline $\begin{array}{l}\text { Disease duration } \\
\text { (years, (mean } \pm S D))\end{array}$ & $11.9 \pm 8.5$ & NA & \\
\hline $\begin{array}{l}\text { SELENA-SLEDAI } \\
(\text { mean } \pm \text { SD) }\end{array}$ & $3.9 \pm 4.0$ & NA & \\
\hline SDI damage $($ mean $\pm S D)$ & $1.3 \pm 1.7$ & NA & \\
\hline
\end{tabular}

*Plus or minus values are mean plus or minus SD.

${ }^{\dagger} \mathrm{p}$ Values shown only if statistically significant.

¥Previously documented CVD is defined a history of myocardial infarction, or CAD documented on angiogram or stress test, or a previous cerebrovascular event, including transient ischaemic attacks (confirmed by a doctor) and stroke (confirmed by appropriate imaging).

${ }^{\S}$ Hypertension was defined as use of antihypertensive drugs or a systolic blood pressure $>140 \mathrm{~mm} \mathrm{Hg}$ or a diastolic blood pressure $>90 \mathrm{~mm} \mathrm{Hg}$.

"Diabetes mellitus was defined as the presence of a fasting glucose $\geq 7.0 \mathrm{mmol} / \mathrm{l}$ $(126 \mathrm{mg} / \mathrm{dl})$, or in subjects receiving insulin or an oral hypoglycaemic agent.

**Smoking was present if subjects had smoked any cigarettes within the past 3 months.

CAD, coronary artery disease; CRP, C-reactive protein; CVD, cardiovascular disease; HDL, high-density lipoprotein; LDL, low-density lipoprotein; SDI, Systemic Lupus International Collaborating Clinics/American College of Rheumatology Damage Index; SLEDAI, Systemic Lupus Erythematosus Disease Activity Index; SELENA, Safety of Estrogens in Lupus Erythematosus-National Assessment.

\section{Statistical analysis}

Data were analysed using SPSS 13.0 (SPSS, Chicago, Illinois, USA, 2005). Skewed continuous variables were logarithmically transformed to attain a normal distribution (note: nontransformed data are presented in figures and tables to facilitate interpretation of results). For variables that did not attain a normal distribution by logarithmic transformation, non-parametric tests were used. Study groups were compared using analysis of variance/Student $t$ test for continuous parametric variables, Mann-Whitney test for non-parametric variables and the $\chi^{2}$ test for categorical variables. Either Pearson or Spearman rank correlation was calculated, depending on whether or not the variable was normally distributed. The significance level was set at 
$\mathrm{p}<0.05$. Multiple regression was used to build models identifying risk factors associated with the presence of plaque and highest quartile of leptin levels in patients with SLE.

\section{RESULTS}

\section{Characteristics of the study groups at baseline}

The SLE and control groups were similar in all demographic variables and risk factors except significantly higher BMI, prevalence of hypertension, diabetes and frequency of cardiovascular events in the SLE group (table 1).

\section{Association of leptin and adiponectin with SLE}

Patients with SLE had significantly higher plasma leptin levels than controls $(\mathrm{p}<0.001)$ (table 1$)$. Because of the known association between high leptin and BMI, subjects were categorised as normal weight (BMI $\leq 24.9)$ or overweight (BMI $\geq 25.0)$. Both normal weight $(p<0.001)$ and overweight patients with SLE $(p<0.001)$ had significantly higher plasma leptin levels than controls (figure 1). Because the overall mean BMI was higher in the SLE group than in the controls, we also performed random matching of SLE and controls in a 2:1 ratio based on BMI. After matching, normal weight $(p=0.001)$ and overweight SLE $(p=0.01)$ subjects still had significantly higher plasma leptin levels than matched controls (online supplementary table 1).

We also examined the relationships between traditional cardiac risk factors, disease activity factors and high leptin using a bivariate model. Patients with SLE with high leptin, defined as the highest quartile of leptin levels ( $\geq 29.5 \mathrm{ng} / \mathrm{ml})$, were significantly more likely to have a higher BMI ( $\mathrm{p}=0.001)$, previous documented CVD ( $p=0.04)$ and a higher SDI $(p=0.04)$ (table 2). However, when the SDI was separated into components, there were no significant associations between leptin and any individual component or organ system.

We next performed logistic regression to examine the relationship between SLE and leptin levels, controlling for potential confounders such as traditional cardiac and other risk factors significantly associated with leptin in our study or in other published studies. After controlling for traditional risk factors,

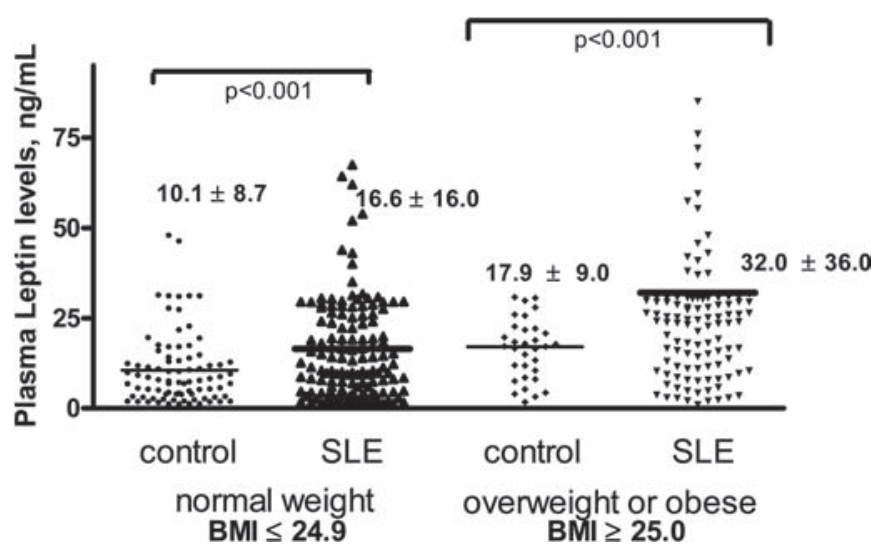

Figure 1 Mean leptin levels are higher in patients with systemic lupus erythematosus (SLE) than in controls, in both normal weight and overweight subjects. Each dot represents leptin levels in individual patients, stratified by control vs SLE and normal weight vs overweight or obese. The heavy horizontal black lines in each column indicate mean scores. Mean leptin levels in each group were then compared using analysis of variance with Dunnet's analysis of comparisons between individual columns
Table 2 Disease characteristics of patients with systemic lupus erythematosus (SLE) in highest quartile leptin levels compared with lowest three quartiles

\begin{tabular}{|c|c|c|c|}
\hline & $\begin{array}{l}\text { Highest } \\
\text { quartile leptin } \\
(\geq 29.5 \mathrm{ng} / \mathrm{ml}) \\
\end{array}$ & $\begin{array}{l}\text { Lowest three } \\
\text { quartiles leptin } \\
\text { (<29.5 ng/ml) }\end{array}$ & \\
\hline Characteristics & $\mathrm{n}=61$ & $n=189$ & p Value \\
\hline Age (years, (mean $\pm S D)$ ) & $44.7 \pm 13.4$ & $41.8 \pm 12.5$ & NS \\
\hline $\begin{array}{l}\text { History of hypertension } \\
(\%(n))\end{array}$ & $31.1(19)$ & $30.7(58)$ & NS \\
\hline History of diabetes (\% (n)) & $4.9(3)$ & $5.3(10)$ & NS \\
\hline $\begin{array}{l}\text { History of smoking } \\
\text { (current) (\% (n)) }\end{array}$ & $6.6(4)$ & $7.9(15)$ & NS \\
\hline $\begin{array}{l}\text { History of previous } \\
\text { cardiovascular } \\
\text { disease }(\%(n))\end{array}$ & $14.8(9)$ & $6.3(12)$ & 0.04 \\
\hline Body mass index & $28.5 \pm 7.1$ & $25.5 \pm 6.1$ & 0.001 \\
\hline Family history of CAD (\% (n)) & $19.7(12)$ & $26.5(50)$ & NS \\
\hline $\begin{array}{l}\text { Previous history of } \\
\text { glomerulonephritis }(\%(n))\end{array}$ & $18.0(11)$ & $28.0(53)$ & NS \\
\hline $\begin{array}{l}\text { Total cholesterol } \\
(\mathrm{mg} / \mathrm{dl},(\text { mean } \pm \mathrm{SD}))\end{array}$ & $196.0 \pm 48.5$ & $184.4 \pm 42.1$ & NS \\
\hline HDL $(\mathrm{mg} / \mathrm{dl},(\operatorname{mean} \pm \mathrm{SD}))$ & $58.0 \pm 17.8$ & $56.4 \pm 16.7$ & NS \\
\hline LDL (mg/dl, (mean \pm SD)) & $115.4 \pm 39.0$ & $105.3 \pm 34.1$ & 0.08 \\
\hline $\begin{array}{l}\text { Triglycerides } \\
\text { (mg/dl, (mean } \pm S D))\end{array}$ & $113.3 \pm 68.4$ & $110.2 \pm 67.7$ & NS \\
\hline History of dyslipidaemia & $19.7(12)$ & $15.3(29)$ & NS \\
\hline $\begin{array}{l}\text { Disease duration } \\
\text { (years, (mean } \pm S D))\end{array}$ & $12.9 \pm 9.2$ & $12.2 \pm 8.0$ & NS \\
\hline SELENA-SLEDAI (mean \pm SD) & $3.8 \pm 3.4$ & $4.0 \pm 4.1$ & NS \\
\hline SDI damage (mean $\pm S D)$ & $1.48 \pm 1.5$ & $1.2 \pm 1.6$ & 0.04 \\
\hline $\begin{array}{l}\text { Intima-media thickness } \\
\left(\mathrm{mm}^{2},(\text { mean } \pm S D)\right)\end{array}$ & $0.57 \pm 0.14$ & $0.54 \pm 0.14$ & NS \\
\hline $\begin{array}{l}\text { Presence of carotid plaque } \\
(y e s, \text { no) }(\%(n))\end{array}$ & $29.5(18)$ & $13.2(25)$ & $<0.003$ \\
\hline $\begin{array}{l}\text { Number of plaques } \\
(\text { mean } \pm S D)\end{array}$ & $0.61 \pm 1.2$ & $0.30 \pm 0.95$ & 0.004 \\
\hline $\begin{array}{l}\text { High sensitivity CRP } \\
\text { (mean } \pm \text { SD) }\end{array}$ & $4.04 \pm 11.1$ & $2.4 \pm 4.8$ & NS \\
\hline $\begin{array}{l}\text { Non-Caucasian } \\
\text { ethnicity (\% (n)) }\end{array}$ & $26.2(16)$ & $22.8(43)$ & NS \\
\hline \multicolumn{4}{|l|}{ Current medication $(\%(n))$} \\
\hline Mycophenolate mofetil & $19.7(12)$ & $23.3(44)$ & NS \\
\hline Hydroxychloroquine & $59.0(36)$ & $62.4(118)$ & NS \\
\hline Cyclophosphamide & $3.3(2)$ & $0.5(1)$ & NS \\
\hline Azathioprine & $6.6(4)$ & $13.8(26)$ & NS \\
\hline $\begin{array}{l}\text { Current prednisone } \\
(\mathrm{mg},(\text { mean } \pm S D))\end{array}$ & $4.8 \pm 9.1$ & $4.3 \pm 7.7$ & NS \\
\hline $\begin{array}{l}\text { 6-Month prednisone } \\
(\mathrm{mg},(\mathrm{mean} \pm \mathrm{SD}))\end{array}$ & $687.0 \pm 1041.1$ & $821.7 \pm 1304.8$ & NS \\
\hline Lp(a) (mg/dl) & $24.9 \pm 25.9$ & $16.9 \pm 9.7$ & 0.01 \\
\hline 0xPL/apoB100 (RLU) & $22035.1 \pm 24583.3$ & $13895.1 \pm 18182.1$ & 0.02 \\
\hline Proinflammatory HDL (\% (n)) & $60.7(37)$ & $49.2(93)$ & $<0.001$ \\
\hline
\end{tabular}

CAD, coronary artery disease; CRP, C-reactive protein; HDL, high-density lipoprotein; LDL, low-density lipoprotein; OxPL/apoB100, oxidised phospholipids on apoB100; SDI, Systemic Lupus International Collaborating Clinics/American College of Rheumatology Damage Index; SELENA, Safety of Estrogens in Lupus ErythematosusNational Assessment; SLEDAl, Systemic Lupus Erythematosus Disease Activity Index; $R L U$, relative light units

including BMI, the OR for having high leptin levels was 2.7 in patients with SLE compared with controls (table 3).

Mean plasma adiponectin levels were not significantly different between patients with SLE and controls in our cohort. Because low adiponectin levels have been associated with cardiovascular risk, we also examined the relationships between low adiponectin, traditional cardiac risk factors and disease activity factors in patients with SLE. Those in the lowest adiponectin quartile had a higher BMI ( $p=0.003)$. No other significant associations between adiponectin levels and cardiac or disease factors were found. 
Table 3 Logistic regression of the relationship of systemic lupus erythematosus (SLE) with the highest quartile of leptin levels

\begin{tabular}{llll}
\hline Explanatory variable & OR & $\mathbf{9 5 \%} \mathbf{C l}$ & p Value \\
\hline SLE diagnosis (yes, no) & 2.7 & 1.3 to 5.9 & 0.01 \\
Age (years) & 1.0 & 0.98 to 1.03 & NS \\
History of dyslipidaemia (yes, no) & 1.3 & 0.6 to 2.7 & NS \\
Hypertension (yes, no) & 0.7 & 0.4 to 1.3 & NS \\
Current smoking (yes, no) & 0.96 & 0.3 to 2.7 & $\mathrm{NS}$ \\
Diabetes (yes, no) & 0.8 & 0.2 to 3.1 & $\mathrm{NS}$ \\
High sensitivity C reactive protein (mg/l) & 1.02 & 0.98 to 1.06 & $\mathrm{NS}$ \\
Body mass index (kg/m ${ }^{2}$ ) & 1.05 & 1.01 to 1.1 & 0.02 \\
Any cardiovascular disease history (yes, no) & 2.7 & 0.98 to 7.3 & 0.06 \\
\hline
\end{tabular}

\section{Correlation between high leptin and proinflammatory lipids}

The relationships between leptin/adiponectin and proinflammatory lipids such as pro-piHDL, PON1, apoA-1, OxPL/apoB100 and $\mathrm{Lp}(\mathrm{a})$ were examined. Mean leptin levels were significantly higher in patients with SLE and with piHDL than in those without piHDL $(26.5 \pm 31.8$ vs $16.1 \pm 17.1, \mathrm{p}<0.001)$, but not in controls $(p=0.18)$. In addition, $60.1 \%$ of patients with SLE with high leptin levels had piHDL, compared with $49.2 \%$ of subjects with lower leptin levels $(\mathrm{p}<0.001)$. There was also a positive correlation between linear HDL function and leptin $(r=0.20, p<0.001)$. Because we have previously shown that piHDL is associated with non-Caucasian ethnicity and lifetime prednisone use $>20 \mathrm{~g}$, we examined whether the association between piHDL and leptin was mediated by the presence of these and other possible confounders, including tobacco use, age, BMI and hypertension. Using logistic regression, we found that the relationship between piHDL and leptin was still significant $(p=0.02)$ (online supplementary table 2). There were no significant relationships between levels of apoA-I or PON1 activity (both protective components of $\mathrm{HDL}$ ). In addition, there was no significant relationship between adiponectin and HDL function.

$\mathrm{Lp}$ (a) levels were also significantly correlated with leptin values ( $r=0.19, p=0.01)$, and were higher in subjects in the highest quartile of leptin levels than in those in the lowest three quartiles $(p=0.01)$. OxPL/apoB100 levels were also higher in patients with SLE with high leptin than in those with low leptin levels $(p=0.02)$ (table 2). OxPL/apoB100 levels were also significantly correlated with continuous leptin levels $(r=0.17, p=0.02)$ (online supplementary figure 1).

\section{Leptin levels are associated with the presence of subclinical atherosclerosis in patients with SLE, even after accounting for traditional cardiac and disease factors}

Among the 250 patients with SLE in this cohort, mean leptin levels were higher in the 43 patients with plaque than in those without plaque $(\mathrm{p}=0.002)$ and were also significantly higher in control subjects with plaque $(p<0.001)$ (figure 2$)$. Bivariate analysis showed that $41.9 \%$ of patients with SLE with plaque had high leptin, compared with $20.8 \%$ of patients with SLE without plaque ( $p=0.003$ ) (online supplementary figure 2 ). The mean number of carotid plaques was also higher in both patients with SLE $(p=0.004)$ (table 2$)$ and controls $(p=0.004)$ with high leptin levels. Mean leptin levels were also weakly correlated with carotid IMT in patients with SLE $(r=0.14, p=0.03)$. There were no associations between leptin levels and plaque location or characteristics in either SLE or control subjects.

Multivariate analysis was used to examine the association of leptin and carotid plaque in patients with SLE after accounting for potential confounders, including traditional cardiac risk factors and SLE associated factors. After analysis, the significant factors

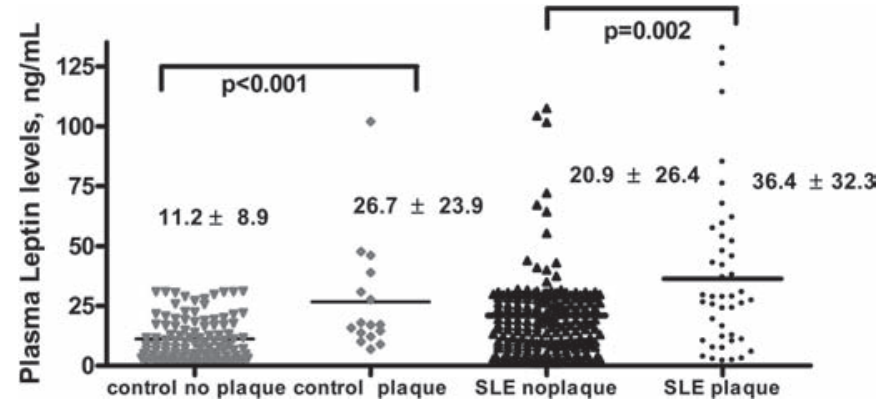

Figure 2 Mean leptin levels are higher in patients with systemic lupus erythematosus (SLE) and control subjects with plaque than in those without plaque. Each dot represents leptin levels in individual patients, stratified by control vs SLE and plaque vs no plaque. The heavy horizontal black lines in each column indicate mean scores.

Table 4 Logistic regression of the relationship of systemic lupus erythematosus with the presence of plaque on carotid ultrasound

\begin{tabular}{lllc}
\hline Explanatory variable & OR & $\mathbf{9 5 \%}$ Cl & p Value \\
\hline Highest quartile leptin (yes, no) & 2.8 & 1.07 to 7.4 & 0.03 \\
$\begin{array}{l}\text { Pro-inflammatory high-density } \\
\text { lipoprotein (yes, no) }\end{array}$ & 12.8 & 3.5 to 47.1 & $<0.001$ \\
Age (years) & 1.1 & 1.07 to 1.2 & $<0.001$ \\
Hypertension (yes, no) & 3.0 & 1.1 to 7.7 & 0.01 \\
Current smoking (yes, no) & 7.7 & 1.4. to 44.0 & 0.03 \\
History of dyslipidaemia (yes, no) & 3.7 & 0.98 to 9.0 & 0.06 \\
Diabetes (yes, no) & 2.0 & 0.2 to 17.2 & NS \\
Body mass index (kg/m ${ }^{2}$ ) & 1.01 & 0.94 to 1.1 & NS \\
Previous documented cardiovascular & 0.54 & 0.2 to 2.6 & NS \\
disease (yes, no) & & & \\
Non-Caucasian ethnicity & 1.9 & 0.7 to 4.9 & NS \\
Lifetime prednisone $>$ 20 g (yes, no) & 2.4 & 0.7 to 8.0 & NS \\
Disease duration & 1.05 & 0.98 to 1.1 & NS \\
SDI & 0.8 & 0.5 to 1.2 & NS \\
\hline
\end{tabular}

hsCRP, high sensitivity C-reactive protein; SDI, Systemic Lupus International Collaborating Clinics/American College of Rheumatology Damage Index.

associated with carotid plaque were high leptin levels, piHDL, age, hypertension and current tobacco use (table 4). The association between high leptin and IMT was no longer significant after controlling for traditional cardiac and SLE disease factors.

\section{Association of adiponectin with plaque in patients with SLE}

Among the 250 patients with SLE in this cohort, mean adiponectin levels were non-significantly higher in patients with SLE with versus without plaque $(17.0 \pm 12.3$ vs $14.6 \pm 7.5, p=0.1)$. There was no significant correlation between adiponectin and carotid IMT in patients with SLE.

\section{DISCUSSION}

SLE is associated with an increased risk of subclinical and clinical atherosclerosis, ${ }^{1-3}$ although the biological mechanisms underlying this risk are not well understood. Data presented here describe high levels of plasma leptin in women with SLE, and an association between high leptin and carotid plaque in bivariate and multivariate analysis. To our knowledge, this is the first study to report a significant association between leptin and subclinical atherosclerosis in SLE. Chung et a P $^{3}$ found no significant relationship between leptin or adiponectin levels and coronary calcification in 109 patients with SLE and 78 control subjects. Possibly, the larger sample size in our study allowed 
us to see significant associations in SLE. Alternatively, it is possible that leptin is associated with plaque in lupus but not with coronary calcification.

In one recently published meta-analysis, the authors concluded that the moderate association between leptin and cardiovascular events in the general population is largely based on BMI. ${ }^{24}$ In our study, although leptin levels correlated with BMI in patients with SLE, multiple analyses controlling for BMI confirmed an independent association between high leptin and carotid plaque. Thus, in our cohort, the influence of leptin on risk of atherosclerosis in SLE appears to be at least partly independent of its association with obesity.

Interestingly, we saw an association between high leptin levels and the proinflammatory lipids piHDL, Lp(a) and OxPL/ apoB100. At least $45 \%$ of patients with SLE have piHDL, and piHDL confers a 16 -fold increased risk of the presence of plaque. ${ }^{1425}$ In this cohort, piHDL was associated with high leptin levels after accounting for the presence of plaque, suggesting an independent association between piHDL and leptin. ${ }^{26}$ Recent animal data from our group supports the idea that leptin may directly promote piHDL formation in an SLE-prone mouse model (BWF1). ${ }^{27}$ The mechanisms that lead to this association, however, are still unclear.

Several authors have suggested that increased oxidative stress may be responsible for the formation of piHDL and other oxidised lipids. ${ }^{28} 29$ Increased leptin levels are known to induce oxidative stress by increasing the accumulation of reactive oxygen species, and serum leptin levels have previously been correlated with oxidised low-density lipoprotein in postmenopausal women. ${ }^{30}$ In our cohort, we also found a correlation between the inflammatory lipids $\mathrm{Lp}(\mathrm{a}), \mathrm{OxPL} / \mathrm{apoB} 100$ and leptin. $\mathrm{Lp}(\mathrm{a})$ is a risk factor for CVD in the general population, and it has been suggested that at least one mechanism by which this occurs is via its content of proinflammatory OxPL.22 31 We have previously shown that nearly all of the OxPL associated with lipoproteins in plasma is associated with $\mathrm{Lp}(\mathrm{a})$ and have proposed that $\mathrm{Lp}(\mathrm{a})$ acts as carrier of such OxPL. Therefore, OxPL/apoB100 probably reflects the biological capacity of $\mathrm{Lp}(\mathrm{a})$ to bind and transport OxPL. Previous studies in SLE have demonstrated an association between OxPL/ apoB100 and CVD ${ }^{32} 33$ and renal disease. ${ }^{33}$ In our cohort, the correlation of $\mathrm{OxPL} / \mathrm{apoB} 100$ and $\mathrm{Lp}(\mathrm{a})$ in patients with SLE was very high $(r=0.96, p<0.0001)$, much higher than previously reported in patients with non-rheumatic disease $(r=0.68, p<0.0001) .{ }^{22}$ Possibly, this suggests that there is an ongoing enhanced state of oxidative stress in patients with SLE, which is reflected in the increased content of $\mathrm{OxPL} / \mathrm{apoB}$ and $\mathrm{Lp}(\mathrm{a})$ and their high correlation with each other. Taken together, these data suggest that leptin contributes to increased oxidation, but further studies are required to determine whether hyperleptinaemia in patients with SLE contributes directly to increased oxidative stress.

There are several other mechanisms by which leptin might directly promote atherosclerosis. Leptin has been shown to increase accumulation of cholesterol esters in foam cells, especially in hyperglycaemic conditions. ${ }^{34}$ It also activates circulating monocytes, induces monocyte proliferation ${ }^{35}$ and upregulates endothelial cell production of monocyte chemoattractant protein $1 .{ }^{26}$ In vitro, leptin treatment stimulates monocyte production of tumour necrosis factor $\alpha$ and interleukin $6 .{ }^{36}$

In addition, leptin levels are inversely associated with physical activity in the general population. ${ }^{37} 38 \mathrm{We}$ previously described a inverse association between physical activity and carotid plaque and increased IMT in subjects with SLE. ${ }^{39}$ Indeed, in this SLE cohort, we found that leptin levels were significantly lower in subjects with high total weekly exercise levels (defined as $\geq 225$ mets/week) $(p<0.001)$. However, even when exercise levels were entered into our multivariate analyses, the significant associations between high leptin, piHDL and plaque in SLE still remained constant (data not shown).

Although low levels of adiponectin have been associated with atherosclerosis, ${ }^{40}$ our study and several previous studies found that plasma adiponectin levels are similar or raised in patients with SLE compared with controls. ${ }^{11}{ }^{41}$ A recent study by Reynolds et al, ${ }^{42}$ also found an association between high adiponectin levels and carotid plaque in SLE; however, we did not find a significant association between adiponectin and plaque in our cohort. It is possible that the exclusion of men and/or the higher proportion of Caucasian subjects in our study may account for this difference.

Our study has some limitations. The prevalence of plaque in our group was lower than in previously published cohorts, ${ }^{2} 43$ and was not significantly different between SLE and control subjects. Possible explanations include our exclusion of individuals taking statins (thus excluding many with known hyperlipidaemia and/or clinical atherosclerosis ${ }^{17}$ ) and inclusion of a higher proportion of Asians, who may have a lower prevalence of atherosclerosis than other racial groups. ${ }^{44}$ Similarly, we did not see any significant difference between mean carotid IMT in SLE and control subjects. This mirrors findings in two other large US SLE cohort studies in which cross-sectional IMT ${ }^{2}$ and IMT progression ${ }^{45}$ did not differ between SLE and controls. In contrast, several smaller European and US studies do demonstrate higher IMT in SLE. ${ }^{42}{ }^{46-48}$ Again, this discrepancy in our cohort might be due to the exclusion of statins. Also, the frequency of smoking in the European studies was much higher than in our group, raising the possibility that tobacco use might play a synergistic role in acceleration of atherosclerosis in SLE.

Finally, our study examines associations between leptin and subclinical atherosclerosis rather than cardiovascular events. Although carotid plaque and IMT are known to be associated with cardiovascular events in the general population, ${ }^{49}$ this association has not been fully established in SLE. Notably, however, although the overall incidence of cardiac events was low in our cohort, previously documented CVD was significantly more common in patients with SLE with carotid plaque $(16.3 \%)$ than in those without $(6.8 \%)(p=0.04)$.

In summary, this study shows that high leptin levels contribute to a 2.8-fold increased odds for the presence of atherosclerosis in female patients with SLE. Future prospective and mechanistic studies are needed to establish leptin as a causative factor for plaque formation in SLE.

Funding Work funded by grants from The Lupus Research Institute (BHH, MM), Alliance for Lupus Research (BHH), American College of Rheumatology/Research and Education Foundation (MM), NIH 1K23AR053864-01A1 (MM), Arthritis Foundation (McMahon), Iris Cantor Women's Health Foundation (MM) and a Kirkland Award (BHH).

Ethics approval This study was conducted with the approval of the UCLA David Geffen School of Medicine.

Provenance and peer review Not commissioned; externally peer reviewed.

\section{REFERENCES}

1. Manzi S, Meilahn EN, Rairie JE, et al. Age-specific incidence rates of myocardial infarction and angina in women with systemic lupus erythematosus: comparison with the Framingham Study. Am J Epidemiol 1997;145:408-15.

2. Roman MJ, Shanker BA, Davis A, et al. Prevalence and correlates of accelerated atherosclerosis in systemic lupus erythematosus. N Engl J Med 2003;349:2399-406. 
3. Esdaile JM, Abrahamowicz M, Grodzicky T, et al. Traditional Framingham risk factors fail to fully account for accelerated atherosclerosis in systemic lupus erythematosus. Arthritis Rheum 2001:44:2331-7.

4. Otero M, Lago R, Gomez R, et al. Towards a pro-inflammatory and immunomodulatory emerging role of leptin. Rheumatology (Oxford) 2006:45:944-50.

5. Garcia-Gonzalez A, Gonzalez-Lopez L, Valera-Gonzalez IC, et al. Serum leptin levels in women with systemic lupus erythematosus. Rheumatol Int 2002;22:138-41.

6. Beltowski J. Leptin and atherosclerosis. Atherosclerosis 2006;189:47-60.

7. Bjørbaek C, Elmquist JK, Frantz JD, et al. Identification of SOCS-3 as a potential mediator of central leptin resistance. Mol Cell 1998;1:619-25.

8. Beltowski J. Role of leptin in blood pressure regulation and arterial hypertension. $J$ Hypertens 2006;24:789-801.

9. Anderson PD, Mehta NN, Wolfe ML, et al. Innate immunity modulates adipokines in humans. J Clin Endocrinol Metab 2007:92:2272-9.

10. Matarese G, Mantzoros C, La Cava A. Leptin and adipocytokines: bridging the gap between immunity and atherosclerosis. Curr Pharm Des 2007:13:3676-80.

11. Sada KE, Yamasaki Y, Maruyama M, et al. Altered levels of adipocytokines in association with insulin resistance in patients with systemic lupus erythematosus. J Reumatol 2006;33:1545-52.

12. Wislowska $\mathbf{M}$, Rok M, Stepien K, et al. Serum leptin in systemic lupus erythematosus. Rheumatol Int 2008:28:467-73.

13. AI M, Ng L, Tyrrell P, et al. Adipokines as novel biomarkers in paediatric systemic lupus erythematosus. Rheumatology (Oxford) 2009;48:497-501.

14. McMahon M, Grossman J, Skaggs B, et al. Dysfunctional proinflammatory highdensity lipoproteins confer increased risk of atherosclerosis in women with systemic lupus erythematosus. Arthritis Rheum 2009;60:2428-37.

15. Hochberg MC. Updating the American College of Rheumatology revised criteria for the classification of systemic lupus erythematosus. Arthritis Rheum 1997;40:1725

16. Walitt BT, Constantinescu F, Katz JD, et al. Validation of self-report of rheumatoid arthritis and systemic lupus erythematosus: the Women's Health Initiative. J Rheumatol 2008;35:811-18

17. Ansell BJ, Navab M, Hama S, et al. Inflammatory/antiinflammatory properties of high-density lipoprotein distinguish patients from control subjects better than high-density lipoprotein cholesterol levels and are favorably affected by simvastatin treatment. Circulation 2003;108:2751-6.

18. Kalantar-Zadeh K, Kopple JD, Kamranpour N, et al. HDL-inflammatory index correlates with poor outcome in hemodialysis patients. Kidney Int 2007;72:1149-56

19. Kim MY, Buyon JP, Petri M, et al. Equivalence trials in SLE research: issues to consider. Lupus 1999;8:620-6.

20. Gladman D, Urowitz M, Fortin P, et al. Systemic Lupus International Collaborating Clinics conference on assessment of lupus flare and quality of life measures in SLE. Systemic Lupus International Collaborating Clinics Group. J Rheumatol 1996;23:1953-5.

21. Eckerson HW, Wyte CM, La Du BN. The human serum paraoxonase/arylesterase polymorphism. Am J Hum Genet 1983;35:1126-38.

22. Fraley AE, Schwartz GG, Olsson AG, et al.; MIRACL Study Investigators. Relationship of oxidized phospholipids and biomarkers of oxidized low-density lipoprotein with cardiovascular risk factors, inflammatory biomarkers, and effect of statin therapy in patients with acute coronary syndromes: results from the MIRACL (Myocardial Ischemia Reduction With Aggressive Cholesterol Lowering) trial. J Am Coll Cardiol 2009;53:2186-96.

23. Chung CP, Long AG, Solus JF, et al. Adipocytokines in systemic lupus erythematosus: relationship to inflammation, insulin resistance and coronary atherosclerosis. Lupus 2009:18:799-806.

24. Sattar N, Wannamethee G, Sarwar N, et al. Leptin and coronary heart disease: prospective study and systematic review. J Am Coll Cardiol 2009:53:167-75.

25. McMahon M, Grossman J, FitzGerald J, et al. Proinflammatory high-density lipoprotein as a biomarker for atherosclerosis in patients with systemic lupus erythematosus and rheumatoid arthritis. Arthritis Rheum 2006;54:2541-9.

26. Bouloumie A, Marumo T, Lafontan M, et al. Leptin induces oxidative stress in human endothelial cells. FASEB J 1999:13:1231-8.

27. Hahn BH, Lourencço EV, McMahon M, et al. Pro-inflammatory high-density lipoproteins and atherosclerosis are induced in lupus-prone mice by a high-fat diet and leptin. Lupus 2010;19:913-17.
28. Vaziri ND, Moradi H, Pahl MV, et al. In vitro stimulation of HDL anti-inflammatory activity and inhibition of LDL pro-inflammatory activity in the plasma of patients with end-stage renal disease by an apoA-1 mimetic peptide. Kidney Int 2009: 76:437-44

29. Yu R, Yekta B, Vakili L, et al. Proatherogenic high-density lipoprotein, vascular inflammation, and mimetic peptides. Curr Atheroscler Rep 2008;10:171-6.

30. Porreca E, Di Febbo C, Moretta V, et al. Circulating leptin is associated with oxidized LDL in postmenopausal women. Atherosclerosis 2004;175:139-43.

31. Tsimikas S, Clopton P, Brilakis ES, et al. Relationship of oxidized phospholipids on apolipoprotein B-100 particles to race/ethnicity, apolipoprotein(a) isoform size, and cardiovascular risk factors: results from the Dallas Heart Study. Circulation 2009:119:1711-19.

32. Frostegård J, Svenungsson $\mathrm{E}, \mathrm{Wu} \mathrm{R}$, et al. Lipid peroxidation is enhanced in patients with systemic lupus erythematosus and is associated with arterial and renal disease manifestations. Arthritis Rheum 2005;52:192-200.

33. Svenungsson $\mathbf{E}$, Jensen-Urstad K, Heimbürger $\mathrm{M}$, et al. Risk factors for cardiovascular disease in systemic lupus erythematosus. Circulation 2001;104:1887-93.

34. O'Rourke L, Gronning LM, Yeaman SJ, et al. Glucose-dependent regulation of cholesterol ester metabolism in macrophages by insulin and leptin. J Biol Chem 2002:277:42557-62.

35. Santos-Alvarez J, Goberna R, Sánchez-Margalet V. Human leptin stimulates proliferation and activation of human circulating monocytes. Cell Immunol 1999;194:6-11.

36. La Cava A, Matarese G. The weight of leptin in immunity. Nat Rev Immunol 2004:4:371-9.

37. Ishii T, Yamakita T, Yamagami K, et al. Effect of exercise training on serum leptin levels in type 2 diabetic patients. Metab Clin Exp 2001;50:1136-40.

38. Jürimäe J, Mäestu J, Jürimäe T, et al. Peripheral signals of energy homeostasis as possible markers of training stress in athletes: a review. Metab Clin Exp 2011;60:335-50

39. Volkmann ER, Grossman JM, Sahakian LJ, et al. Low physical activity is associated with proinflammatory high-density lipoprotein and increased subclinical atherosclerosis in women with systemic lupus erythematosus. Arthritis Care Res (Hoboken) 2010;62:258-65.

40. Maahs DM, Ogden LG, Kinney GL, et al. Low plasma adiponectin levels predict progression of coronary artery calcification. Circulation 2005;111:747-53.

41. Rovin BH, Song H, Hebert LA, et al. Plasma, urine, and renal expression of adiponectin in human systemic lupus erythematosus. Kidney Int 2005; 68:1825-33.

42. Reynolds HR, Buyon J, Kim M, et al. Association of plasma soluble E-selectin and adiponectin with carotid plaque in patients with systemic lupus erythematosus. Atherosclerosis 2010:210:569-74.

43. Manzi S, Selzer F, Sutton-Tyrrell K, et al. Prevalence and risk factors of carotid plaque in women with systemic lupus erythematosus. Arthritis Rheum 1999:42:51-60.

44. Carnethon MR, Bertoni AG, Shea S, et al. Racial/Ethnic differences in subclinical atherosclerosis among adults with diabetes: the multiethnic study of atherosclerosis. Diabetes Care 2005;28:2768-70.

45. Thompson T, Sutton-Tyrrell K, Wildman RP, et al. Progression of carotid intima-media thickness and plaque in women with systemic lupus erythematosus. Arthritis Rheum 2008;58:835-42.

46. Cacciapaglia F, Zardi EM, Coppolino G, et al. Stiffness parameters, intima-media thickness and early atherosclerosis in systemic lupus erythematosus patients. Lupus 2009;18:249-56

47. Colombo BM, Cacciapaglia F, Puntoni M, et al. Traditional and non traditional risk factors in accelerated atherosclerosis in systemic lupus erythematosus: role of vascular endothelial growth factor (VEGATS Study). Autoimmun Rev 2009:8:309-15

48. de Leeuw K, Smit AJ, de Groot E, et al. Longitudinal study on premature atherosclerosis in patients with systemic lupus erythematosus. Atherosclerosis 2009;206:546-50.

49. Hodis HN, Mack WJ, LaBree L, et al. The role of carotid arterial intima-media thickness in predicting clinical coronary events. Ann Intern Med 1998;128:262-9. 